\title{
Correction to: Abnormally elevated USP37 expression in breast cancer stem cells regulates stemness, epithelial-mesenchymal transition and cisplatin sensitivity
}

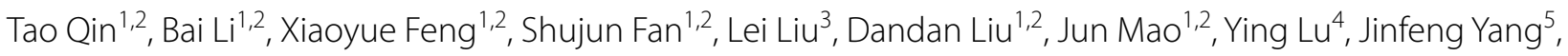
Xiaotang Yu' ${ }^{1}$, Qingqing Zhang ${ }^{1}$, Jun Zhang ${ }^{6}$, Bo Song ${ }^{1,2}$, Man Li ${ }^{7^{*}}$ and Lianhong $\mathrm{Li}^{1,2^{*}}$

Correction to: J Exp Clin Cancer Res 37, 287 (2018)

https://doi.org/10.1186/s13046-018-0934-9

Following publication of the original article [1], the authors identified minor errors in Fig. 6; specifically, in Fig. 6D, the incorrect transwell analysis image was used for the siUSP37\#2 group without purmorphamine (bottom left image).

The corrected figure is provided here. The correction does not have any effect on the results or conclusions of the paper. The original article has been corrected.
Second Affiliated Hospital of Dalian Medical University, Dalian 116023, Liaoning Province, People's Republic of China.

Published online: 09 November 2021

\section{Reference}

1. Qin T, Li B, Feng X, et al. Abnormally elevated USP37 expression in breast cancer stem cells regulates stemness, epithelial-mesenchymal transition and cisplatin sensitivity. J Exp Clin Cancer Res. 2018;37:287. https://doi. org/10.1186/s13046-018-0934-9.

\begin{abstract}
Author details
'Department of Pathology, Dalian Medical University, Dalian 116044, People's Republic of China. ${ }^{2}$ The Key Laboratory of Tumor Stem Cell Research of Liaoning Province, Dalian Medical University, Dalian 116044, People's Republic of China. ${ }^{3}$ Department of Urology, The First Affiliated Hospital of Dalian Medical University, Dalian, People's Republic of China. ${ }^{4}$ Teaching Laboratory of Morphology, Dalian Medical University, Dalian 116044, People's Republic of China. ${ }^{5}$ Department of Pathology, Xiangyang Central Hospital, Xiangyang 441000, People's Republic of China. ${ }^{6}$ Department of Dean, Dalian Medical University, Dalian 116044, People's Republic of China. ${ }^{7}$ Department of Oncology, The
\end{abstract}

The original article can be found online at https://doi.org/10.1186/s13046018-0934-9.

\footnotetext{
*Correspondence: liman19890930@sina.com; lilianhong917@sina.com

${ }^{2}$ The Key Laboratory of Tumor Stem Cell Research of Liaoning Province, Dalian Medical University, Dalian 116044, People's Republic of China ${ }^{7}$ Department of Oncology, The Second Affiliated Hospital of Dalian Medical University, Dalian 116023, Liaoning Province, People's Republic of China

Full list of author information is available at the end of the article
}

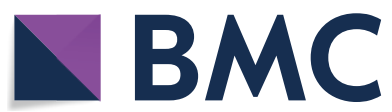

(c) The Author(s) 2021. Open Access This article is licensed under a Creative Commons Attribution 4.0 International License, which permits use, sharing, adaptation, distribution and reproduction in any medium or format, as long as you give appropriate credit to the original author(s) and the source, provide a link to the Creative Commons licence, and indicate if changes were made. The images or other third party material in this article are included in the article's Creative Commons licence, unless indicated otherwise in a credit line to the material. If material is not included in the article's Creative Commons licence and your intended use is not permitted by statutory regulation or exceeds the permitted use, you will need to obtain permission directly from the copyright holder. To view a copy of this licence, visit http://creativecommons.org/licenses/by/4.0/. The Creative Commons Public Domain Dedication waiver (http://creativeco mmons.org/publicdomain/zero/1.0/) applies to the data made available in this article, unless otherwise stated in a credit line to the data. 


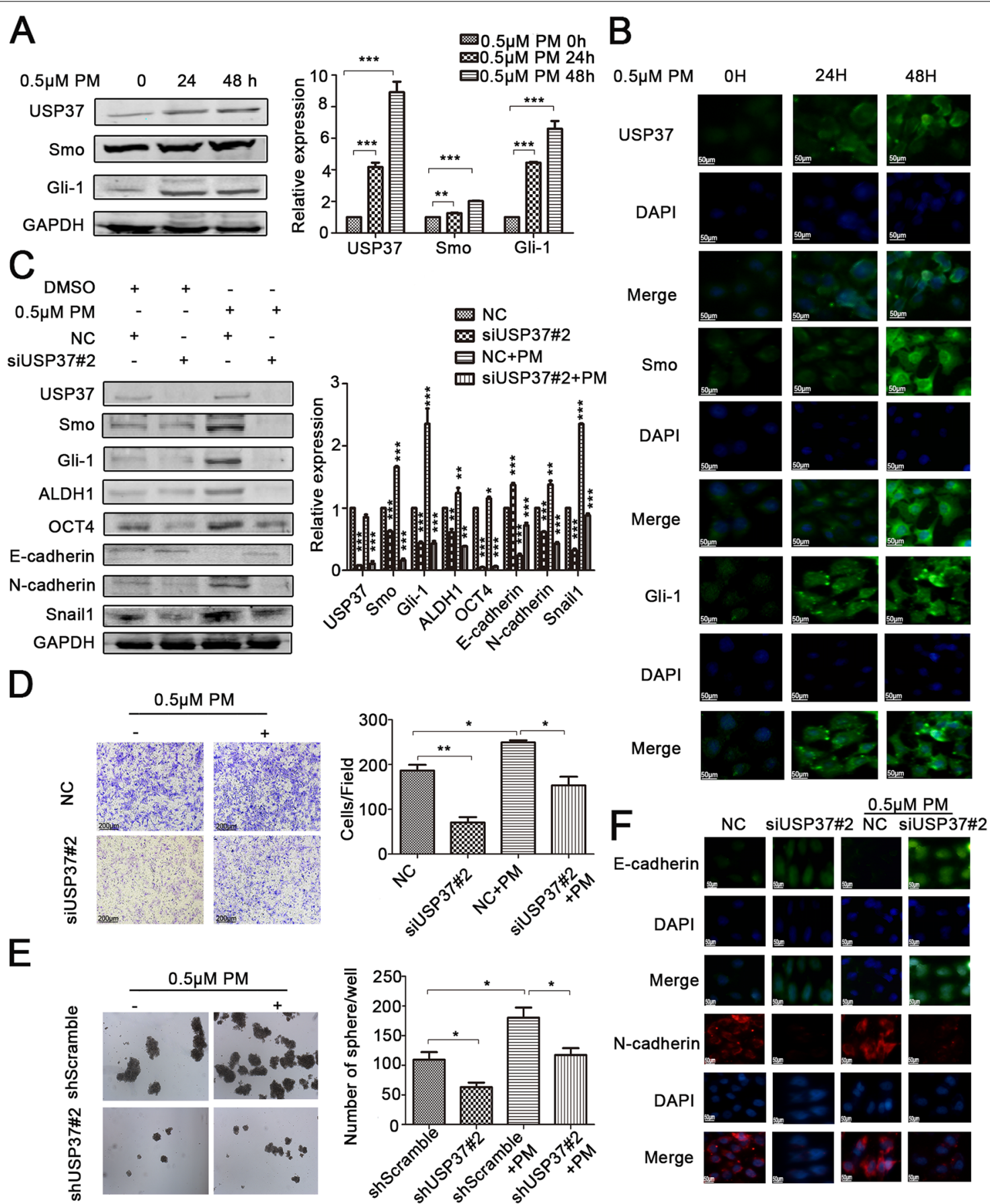

Fig. 6 USP37 knockdown inhibits stemness, cell invasion and EMT via Hedgehog signaling pathway in breast cancer. a, b MCF-7 cells were incubated with $0.5 \mu \mathrm{M}$ purmorphamine for 24 and $48 \mathrm{~h}$. a Hedgehog pathway constituents were examined via western blotting. GAPDH was examined as a loading control. ${ }^{*} P<0.01,{ }^{* *} P<0.001$. b Immunofluorescence staining images of MCF-7 cells showed the expression of USP37 and Hedgehog pathway constituents. c Protein levels of USP37, Smo, Gli-1, ALDH1, OCT4, E-cadherin, N-cadherin, Snail1 as detected by western blotting after the NC siRNA group or the USP37 siRNA\#2 group was treated with $0.5 \mu \mathrm{M}$ purmorphamine for $48 \mathrm{~h}$. GAPDH was examined as a loading control. ${ }^{* *} P<0.01,{ }^{* *} P<0.001$. d Cell invasion capacity of the NC siRNA group or the USP37 siRNA\#2 group treated with $0.5 \mu M$ purmorphamine (Scale bar: $200 \mu \mathrm{m}$ ). e Spheroid formation capacity of MCF-7-ShScramble or MCF-7-shUSP37\#2 cells treated with $0.5 \mu$ M purmorphamine (original magnification, $4 \times$ ). $\mathbf{f}$ Immunofluorescence staining of E-cadherin and N-cadherin after the NC siRNA group or the USP37 siRNA\#2 group treated with $0.5 \mu \mathrm{M}$ purmorphamine for $48 \mathrm{~h}$. (Scale bar: $50 \mu \mathrm{m}$ ). ${ }^{*} P<0.05$, ${ }^{* *} P<0.01$ 